\title{
Quality of Life and Psychopathology in Lichen Planus: A Neglected Disease Burden
}

Zeno FIOCCO ${ }^{1}$, Sophie KUPF ${ }^{1}$, Leilah PATZAK ${ }^{1}$, Till KÄMMERER ${ }^{1}$, Teodora PUMNEA ${ }^{1}$, Lars E. FRENCH ${ }^{1,2}$ and Markus REINHOLZ ${ }^{1}$ ${ }^{1}$ Department of Dermatology and Allergy, University Hospital, Ludwig Maximillian University, Munich, Germany, and ${ }^{2}$ Dr Phillip Frost Department of Dermatology and Cutaneous Surgery, University of Miami, Miller School of Medicine, Miami, FL, USA

\begin{abstract}
The disease burden of lichen planus and its impact on patients' quality of life have not been well studied. The aim of this mono-centre cross-sectional study was to investigate these factors. From June to September 2020, an anonymous survey was posted to 253 patients, who were diagnosed with lichen planus in our outpatient clinic from January 2018 to June 2020. Quality of life was evaluated using the Dermatology Life Quality Index (DLQI), the EuroQol 5-dimension 3-level score, and further quality of life indicators. Beck Depression Inventory II was used to evaluate symptoms of depression. A total of 100 patients completed and returned the survey. Lichen planus affected quality of life in $\mathbf{7 8 \%}$ of cases. DLQI was higher for multiple localizations $(r=0.454, p<0.001)$. Patients with genital lichen planus had a significantly higher DLQI (mean \pm standard deviation (SD) 8.68 \pm 6.96 ) than patients who were not affected in the genital area (5.01 $\pm 5.49 ; p=0.009)$. DLQI was also significantly higher for ungual lichen planus $\mathbf{( 9 . 8 3} \pm \mathbf{7 . 6}$; not affected: $5.65 \pm 5.84 ; p$-value 0.039 ), and for cutaneous LP (mean 8.1, SD 6.22; not affected: $5.63 \pm 6.12$; $p$-value $0.045)$. Twenty-nine percent of patients had mild to moderate symptoms of depression, and $6 \%$ had severe symptoms of depression. Depression and reduced quality of life are an undetected and relevant burden affecting patients with lichen planus.
\end{abstract}

Key words: lichenoid eruptions; scalp dermatoses; depression; DLQI; psychodermatology.

Accepted Oct 26, 2021; Epub ahead of print Oct 26, 2021

Acta Derm Venereol 2021; 101: adv00619.

Corr: Zeno Fiocco, Department of Dermatology and Allergy, University Hospital, LMU Munich, Frauenlobstr. 9-11, DE-80337 Munich, Germany. E-mail: Zeno.Fiocco@med.uni-muenchen.de

$\mathrm{L}$ ichen planus (LP) is a heterogeneous idiopathic mucocutaneous inflammatory disease with variable intensity and extent of symptoms, lesions, localization, and frequency. The most frequently involved areas are the skin and oral mucosa. Other mucous membranes (including the genitalia, oesophagus, and conjunctiva) and skin appendages (i.e. hair follicles and nails) can be affected. Multiple areas can be involved, either concomitantly or sequentially (1).

Classic cutaneous LP is characterized by pruritic, violaceous papules affecting the extremities and the lower back. On the scalp, LP may evolve towards scar-

\section{SIGNIFICANCE}

Depression and reduced quality of life are an undetected burden that significantly affects patients with lichen planus. Physicians need to be aware of these associations and screen for them in order to plan the course of management of patients with lichen planus, with the aim of improving prognosis and therapeutic success. Through recognition of patients' needs we can suggest methods to improve clinical practice, thus enhancing quality of life in patients with lichen planus.

ring alopecia. Nails affected by LP may appear atrophic or dystrophic with longitudinal ridging and fissuring. On the oral mucosa LP may present as whitish striae (so-called Wickham striae), in the genital area the manifestation is characterized by erythema, papules, and/or erosions. The erosive form of mucosal LP may result in fibrosis, with vulvar scarring, vaginal stenosis, phimosis, oesophageal stricture, blindness, or obstruction of the lachrymal canal (1). Although its incidence varies depending on geographical location, cutaneous LP has been reported to affect $0.2-1 \%$ of the adult population, whereas oral lesions have been observed in $0.49-1.43 \%$ of the general population $(2,3)$. The onset of LP occurs most commonly during the fifth or sixth decade, with two-thirds of patients developing the disease between the ages of 30 and 60 years. A large study of patients who presented with oral lesions revealed prior or current cutaneous lesions in $16 \%$ and genital disease in $19 \%$ (1).

The number of studies evaluating quality of life (QoL) in cutaneous LP is low (4-6). Few studies concerning the oral and genital forms of the disease have been published (7-10). Consideration of this skin condition thus appears to be minor, despite the fact that it is part of dermatological daily routine. It was hypothesized that, along with the skin condition, our patients might experience problems with body image, self-esteem, self-concept, and have feelings of stigma, shame and embarrassment regarding their appearance, as well as suicidal thoughts, similar to patients with psoriasis (11-13). Higher prevalences of mixed anxiety-depressive disorder, social phobia, panic symptoms, obsessive thoughts and dysthymia have also been reported in patients with LP (14).

The aim of this study was to survey QoL in patients affected by LP in our dermatology department and ex- 
plore further psychopathological associations with sex differences.

\section{MATERIALS AND METHODS}

From June to September 2020 we posted an anonymous questionnaire to $253 \mathrm{LP}$ patients treated in our outpatient clinic from January 2018 to June 2020.

Information on demographics (sex, body mass index (BMI), marital status, educational background, health insurance), diagnosis (time of diagnosis, localization), systemic diseases and lifestyle habits (alcohol, smoking), stress level, treatment, medication, and patients' suggestions for improvement were collected. The stress level was represented in a range between 0 (no stress) and 10 (extremely stressful situation). Moreover, this survey included the Dermatology Life Quality Index (DLQI) (14), the EuroQol Group 5-dimension 3-level questionnaire (EQ-5D-3L) score, the Beck Depression Inventory II (BDI-II) and further not standardized questions designed in our centre to investigate QoL indicators, which are shown in Table I. The study was approved by the local ethics committee (ethics committee University Hospital, LMU Munich, Germany, reference number 20-421).

\section{Dermatology Life Quality Index}

DLQI is a widely used questionnaire that aims to measure the impact of skin disease on QoL of adult patients. The DLQI consists of 10 items covering 6 basic topics: symptoms and feelings, daily activities, leisure, work or school, personal relationships, and treatment, each rated on a 4-point Likert rating. DLQI is calculated by collecting the sum of the scores of the above questions. Higher scores are associated with greater impairment of QoL. DLQI score ranges from a minimum of 0 to a maximum of 30 (15). A free license (license ID CUQQoL2590) has been granted for the purposes of the current study.

\section{EuroQol Group 5D-3L questionnaire}

The EQ-5D-3L is a standardized generic instrument developed for describing and valuing health states. The score consists of a visual analogue scale (EQ VAS) and a descriptive system, comprising 5 dimensions, with each representing a different aspect of health:

\section{Table I. Quality of life indicators}

\begin{tabular}{|c|c|c|c|}
\hline & $\begin{array}{l}\text { Total } \\
\%\end{array}$ & $\begin{array}{l}\text { Male } \\
\%\end{array}$ & $\begin{array}{l}\text { Female } \\
\%\end{array}$ \\
\hline \multicolumn{4}{|c|}{ Patients with one of the following symptoms in the 4 weeks prior to the survey } \\
\hline Pain $(n=99)$ & 57.7 & 50 & 60 \\
\hline Ulcerations $(n=99)$ & 47.4 & 40.9 & 49.3 \\
\hline Scarring $(n=97)$ & 38.9 & 43.5 & 37.5 \\
\hline Influence on sexual activity $(n=97)$ & 20 & 34.8 & 15.3 \\
\hline Body image disturbance $(n=99)$ & 52.6 & 56.5 & 51.4 \\
\hline Sense of shame $(n=99)$ & 49.5 & 56.5 & 47.3 \\
\hline Refusal of body contact $(n=98)$ & 27.1 & 34.8 & 24.7 \\
\hline Influence on body hygiene $(n=98)$ & 31.3 & 30.4 & 31.5 \\
\hline Limitation in school or work activities $(n=98)$ & 24 & 17.4 & 26 \\
\hline Influence on leisure or hobby activities $(n=98)$ & 33.3 & 21.7 & 37 \\
\hline Impairment in basic activities of daily living $(n=99)$ & 30.9 & 26.1 & 32.4 \\
\hline \multicolumn{4}{|c|}{$\begin{array}{l}\text { Patients suffering during the total duration of the illness from one of the } \\
\text { following symptoms }\end{array}$} \\
\hline Influence on sexual relationships $(n=100)$ & 19.4 & 39.1 & 13.3 \\
\hline Influence of desire to have children $(n=99)$ & 2.1 & 0 & 2.7 \\
\hline Depression/feeling of anxiety $(n=98)$ & 64.6 & 60.9 & 65.8 \\
\hline Influence on work life or search for a job $(n=99)$ & 8.2 & 13 & 6.8 \\
\hline Influence on personal finances $(n=99)$ & 20.6 & 21.7 & 20.3 \\
\hline
\end{tabular}

mobility, self-care, usual activities, pain or discomfort, anxiety and depression. Each dimension has 3 levels: no problems, some problems, and extreme problems (16). The EQ VAS records the patient's self-rated health on a vertical visual analogue scale, ranging from 0 to 100 points, where the endpoints are labelled "Best imaginable health state" and "Worst imaginable health state". Use of the EQ-5D-3L was approved for this study by the EuroQol Research Foundation.

\section{Beck's Depression Inventory II}

BDI-II was devised by Beck in 1996 (16). It contains 21 sentence groups aimed at assessing the level of depression. BDI-II was not developed to diagnose depression, and the score was not used for this purpose in the current study. The 21 symptoms of depression included in the scale are listed in Table II. Each category receives a score of $0-3$ points. The standardized cut-offs are: $0-13$ (minimal depression), 14-19 (mild depression), 20-28 (moderate depression), and 29-63 (severe depression) (17).

Further questions investigating indicators of QoL were also applied to the study particpants (Table I).

\section{Statistical analysis}

The data were analysed by a statistician, with IBM SPSS Statistics (Version 26.0) predictive analytics software $(18,19)$, using Mann-Whitney $U$ test, Fisher's exact test, rank correlation, $\chi^{2}$ test and Shapiro-Wilk test. $p$-values $<0.05$ were considered significant. Results at $p<0.01$ were considered highly significant and, if the value ranged between 0.05 and $0.1(20-26)$, weakly significant.

\section{RESULTS}

This anonymous survey was sent to 253 patients who presented with a diagnosis of LP in our outpatient clinic within 3 years prior to the study. In total, 100 patients completed the survey, which corresponds to a return rate of $39.56 \%$. However, not all participants answered every single question in the survey.

Table II. Patients with symptoms of depression included in Beck Depression Inventory II (BDI-II)

\begin{tabular}{llll}
\hline & $\begin{array}{l}\text { Total } \\
\%\end{array}$ & $\begin{array}{l}\text { Male } \\
\%\end{array}$ & $\begin{array}{l}\text { Female } \\
\%\end{array}$ \\
\hline Sadness $(n=95)$ & 49.5 & 34.8 & 54.3 \\
Pessimism $(n=96)$ & 39.4 & 30.4 & 42.3 \\
Past failure $(n=95)$ & 28 & 13 & 32.9 \\
Loss of pleasure $(n=97)$ & 58.9 & 43.5 & 63.9 \\
Guilty feelings $(n=94)$ & 27.2 & 17.4 & 30.4 \\
Punishment feelings $(n=96)$ & 22.3 & 8.7 & 26.8 \\
Self-dislike $(n=94)$ & 21.7 & 21.7 & 21.7 \\
Self-criticalness $(n=95)$ & 32.3 & 17.4 & 37.1 \\
Suicidal thoughts or wishes $(n=96)$ & 14.9 & 13 & 15.5 \\
Crying $(n=96)$ & 29 & 17.4 & 32.9 \\
Agitation $(n=97)$ & 38.9 & 26.1 & 43.1 \\
Loss of interest $(n=98)$ & 36.5 & 26.1 & 39.7 \\
Indecisiveness $(n=97)$ & 35.8 & 26.1 & 38.9 \\
Worthlessness $(n=97)$ & 25.3 & 17.4 & 27.8 \\
Loss of energy $(n=98)$ & 54.2 & 34.8 & 60.3 \\
Changes in sleeping pattern $(n=98)$ & 45.8 & 36.4 & 48.6 \\
Irritability $(n=98)$ & 39.6 & 21.7 & 45.2 \\
Changes in appetite $(n=98)$ & 31.3 & 26.1 & 32.9 \\
Concentration difficulty $(n=98)$ & 52.1 & 34.8 & 57.5 \\
Tiredness or fatigue $(n=96)$ & 55.3 & 34.8 & 62 \\
Loss of interest in sex $(n=95)$ & 51.6 & 30.4 & 58.6 \\
\hline
\end{tabular}




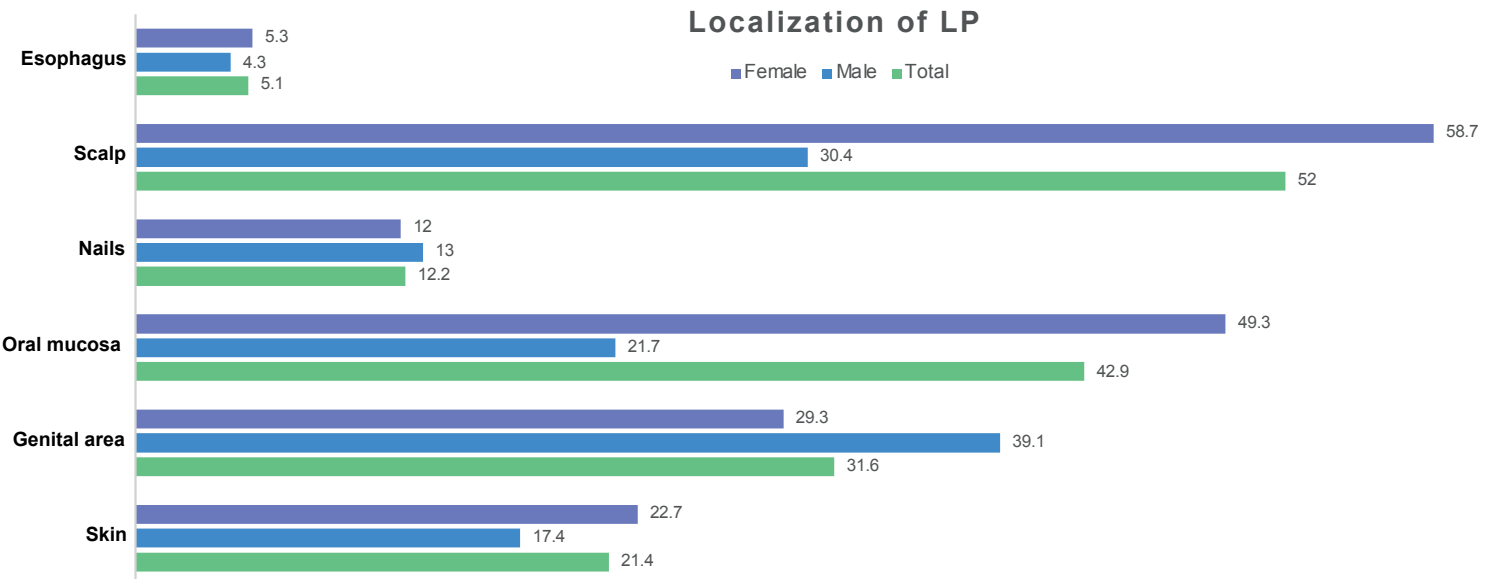

Fig. 1. Localization of lichen planus (LP) is shown as percentage (\%) for the total of cases and for each sex separately. In $40 \%$ of cases at least 2 localizations were affected, while $15 \%$ of cases presented at least 3 (data not shown). In male patients, cutaneous and enoral LP were not associated. Number of replies $=98$.

\section{Sample description}

More participants were female (76.53\%). Mean \pm standard deviation (SD) age at diagnosis of LP was $47.9 \pm 11.8$ years for men and $55.3 \pm 14.9$ years for women. In $55.4 \%$ of patients, the skin condition was initially misdiagnosed, with no significant difference among sexes. The condition was diagnosed by a dentist in $19.4 \%$ of patients, by a dermatologist in $69.4 \%$, by a general practitioner in $3.1 \%$, and was first noted by a hairdresser in 3.1\% of cases. Other specialists, e.g. urologists or gynaecologists, diagnosed $11.2 \%$ of cases. The distribution of LP localization is shown in Fig. 1. In $40 \%$ of patients at least 2 localizations were affected, while, in $15 \%$ of cases, there were at least 3 localizations. In male patients, cutaneous and enoral LP never occurred simultaneously. An extensive sample description is shown in Table III.

\section{Stress level}

Stress affected $65.2 \%$ of male and $65.8 \%$ of female respondents. No significant differences were observed between the sexes, since mean and mode, respectively,

Table III. Demographic characteristics

\begin{tabular}{llll}
\hline & Total & Male & Female \\
\hline $\begin{array}{l}\text { Sex }(n=98), \% \\
\text { BMI, } \mathrm{kg} / \mathrm{m}^{2}(n=92),\end{array}$ & 100 & 23.47 & 76.53 \\
$\quad$ mean \pm SD & $26.239 \pm 5.931$ & $26.805 \pm 4.606$ & $26.072 \pm 6.288$ \\
$\begin{array}{l}\text { Age at diagnosis, years } \\
\quad(n=74), \text { mean } \pm \text { SD }\end{array}$ & $53.73 \pm 14.51$ & $47.88 \pm 11.77$ & $55.34 \pm 14.86$ \\
$\begin{array}{l}\text { Marital status }(n=96), \% \\
\text { Married }\end{array}$ & & & \\
Single & 63.5 & 69.6 & 61.5 \\
Separated & 16.7 & 21.7 & 15.1 \\
$\quad$ Widowed & 9.4 & 4.3 & 11.0 \\
$\quad$ Dating & 9.4 & 0.0 & 12.3 \\
Educational background $(n=84), \%$ & 4.3 & 0.0 \\
$\quad$ General education & 22.6 & 30 & 20.3 \\
Higher secondary level & 61.9 & 45 & 67.2 \\
education & & & \\
University degree & 15.5 & 25 & 12.5 \\
\hline
\end{tabular}

BMI: body mass index; SD: standard deviation. were $5.9 \pm 1.8$ and 7.0 in male patients and $6.5 \pm 2.0$ and 8.0 in female patients. The current study did not explicitly investigate whether the development of LP was associated with a stressful event, as reported in other studies $(27,28)$.

\section{Dermatology Life Quality Index}

While $22 \%$ of patients reported that LP had no impact on their QoL, the majority (78\%) declared that their lives were somehow affected (Fig. 2). In 24\% of patients, the effect was small (DLQI 2-5) and in 15\% moderate (DLQI 6-10). The remainder of patients in the current study reported a major impact on their lives $(16 \%$ very large and $7 \%$ extremely large, i.e. DLQI from 11 to 20 and from 21 to 30, respectively).

Patients with genital LP had a significantly higher DLQI (mean \pm SD $8.68 \pm 6.96)$ than patients not affected in the genital area $(5.01 \pm 5.49 ; p=0.009)$. DLQI was also significantly higher for ungual LP $(9.83 \pm 7.6$; not affected: mean $5.65 \pm 5.84 ; p$-value 0.039$)$, and for cu-

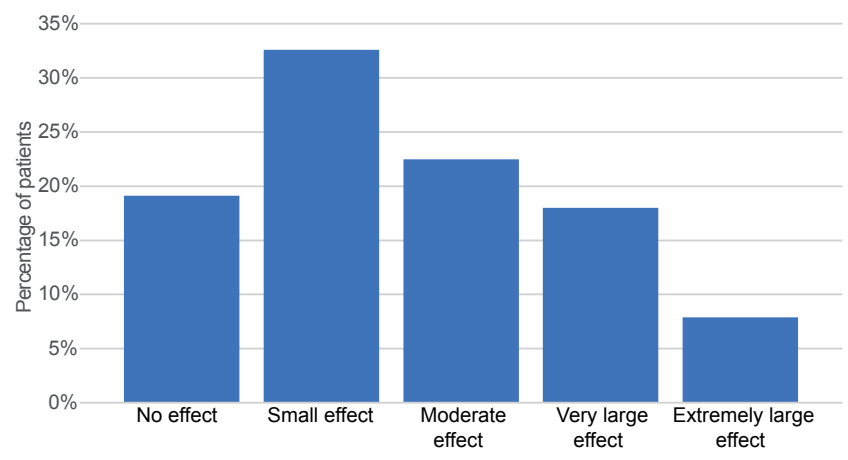

Fig. 2. Dermatology Life Quality Index (DLQI) score (values 0-30) was used to analyse the quality of life associated with lichen planus (LP). The majority of patients (78\%) responded that their lives were somehow affected, in particular the impact was reported to be small $(24 \%$, DLQI $2-5)$, moderate (15\%, DLQI 6-10), very large $(16 \%, 11-20)$ and extremely large $(7 \%, 21-30)$. Only $22 \%$ of respondents reported no effect on quality of life (QoL) (DLQI 0-1). Number of replies $=100$. 
Table IV. EuroQol Group 5D-3L questionnaire (EQ-5D-3L) descriptive system

\begin{tabular}{|c|c|c|c|c|c|c|c|c|c|}
\hline & \multicolumn{3}{|c|}{ Total } & \multicolumn{3}{|l|}{ Male } & \multicolumn{3}{|c|}{ Female } \\
\hline & 1 & 2 & 3 & 1 & 2 & 3 & 1 & 2 & 3 \\
\hline Mobility $(n=97), \%$ & 81.4 & 18.6 & 0 & 91.3 & 8.7 & 0 & 78.4 & 21.6 & 0 \\
\hline Self-care $(n=98), \%$ & 94.9 & 5.1 & 0 & 95.7 & 4.3 & 0 & 94.7 & 5.3 & 0 \\
\hline Usual activities $(n=97), \%$ & 82.5 & 17.5 & 0 & 91.3 & 8.7 & 0 & 79.7 & 20.3 & 0 \\
\hline Pain/discomfort $(n=96), \%$ & 30.2 & 61.5 & 8.3 & 43.5 & 52.2 & 4.3 & 26 & 64.4 & 9.6 \\
\hline Anxiety/depression $(n=98), \%$ & 40.8 & 50 & 9.2 & 52.2 & 39.1 & 8.7 & 37.3 & 53.3 & 9.3 \\
\hline
\end{tabular}

The EQ-5D-3L descriptive system comprises the following 5 dimensions: mobility, selfcare, usual activities, pain/discomfort, and anxiety/depression. Each dimension has 3 levels: no problems, some problems, and extreme problems.

taneous LP $(8.1 \pm 6.22$; not affected: $5.63 \pm 6.12 ; p$-value $0.045)$. DLQI was also higher for multiple localizations $(\mathrm{r}=0.454, p<0.001)$.

\section{EuroQol 5-dimensions 3-level score}

The EQ-5D-3L tool was used to measure health-related QoL in the current study group that was not only related to the dermatological disease. Overall, no patient described extreme problems in mobility, self-care or usual activities. Of participants, $18.6 \%$ reported a reduction in mobility and $17.5 \%$ in their usual activities. Pain or a sensation of discomfort affected $69.8 \%$ of patients $(8.3 \%$ to an extreme degree), while $59.2 \%$ of patients experienced depression or anxiety. As for the EQ VAS tool, the mean value of the total cases was 65.29 and males had significantly higher scores, with a total mean of 73.48 (vs 65.29 in females). The results are shown in Table IV.

\section{QoL indicators}

Further indicators of QoL, not included in the standardized scores above, were investigated as related to LP only. The results are shown in Table I and Table $\mathbf{V}$.

\section{Beck's Depression Inventory II}

In the current study group, $17 \%$ of patients showed symptoms of moderate depression and $12 \%$ of mild depression, while $6 \%$ of respondents (only female) had a BDI-II score suggesting a severe degree of depression. The majority of patients analysed met criteria for a minimal severity of depression. Loss of sexual interest was one of the most common symptoms among female patients $(58.6 \%)$. The results are shown in Table II.

\section{Patients' suggestions for improvement}

More than half of the patients wanted better information about the disease $(54.1 \%)$ and $48.0 \%$ of patients wanted better information about the therapy; $20 \%$ of the interviewed population stated that information material might be a useful tool. Of female patients, $34.7 \%$, wished to establish a net of interdisciplinary specialists in LP, compared with only $13 \%$ of males.

\section{DISCUSSION}

To date, the impact of LP on QoL, as well as its psychopathological associations, have been poorly investigated (4). The current study sought to further investigate these 2 aspects of LP. The results show that LP has a major impact on QoL of patients. Although the current study did not investigate the role of stress as an aetiological factor $(5,27-30)$, two-thirds of patients reported suffering from stress with a considerable stress level (over 5/10).

The high level of impact of LP might be due to the high prevalence of pain, ulcerations, scar formation, and the influence of LP on hygiene. Thus, LP can broadly influence multiple aspects of patients' lives, such as sexual activity, body image perception and lead to a feeling of shame and refusal of body contact. Nineteen percent of patients reported no influence of LP on sexual relationships. The desire to have children was affected in $2.7 \%$ of women. A positive correlation was observed between disease burden, the number of affected body areas, and a strong impact on QoL.

LP has strong impact on the socioeconomic status of affected patients: $24 \%$ of patients described limitations in school or work activities, $33.3 \%$ on leisure and hobby activities, and $30.9 \%$ were impacted by their disease even in their daily life. An influence on work life or on job searching was reported by $8.2 \%$ of cases, and in $20 \%$ of cases their personal finances were affected. This data is comparable with previous studies (31).

In addition, this study addressed the psychopathological health of the patients. Although only 4 patients in the current study $(4.1 \%$, i.e. 1 male and 3 females) reported a clinically 
diagnosed depression, at least $65 \%$ of patients showed minimal symptoms, while $29 \%$ had mild to moderate and $6 \%$ severe symptoms of depression. Similarly, 59.2\% of respondents reported having depression and anxiety (EQ-5D-3L), and similar results $(64.6 \%)$ were obtained when asking specifically about depression state or feelings of anxiety with regard to LP. It must be taken into account that some of the study patients were affected by comorbidities; for instance, $25.5 \%$ had another chronic disease and $18.4 \%$ had oncological diseases. However, we do not consider that this would explain the high prevalence of depressive symptoms in the current group, which we consider is associated with LP.

The rate of depression and anxiety in the current study cohort is higher than that found in a recent multicentre study investigating common skin diseases (6). Dalgard et al. (6) found rates of $10.1 \%$, and $17.2 \%$ using the Hospital Anxiety and Depression Scale (HADS). Interestingly, the current cohort showed an even higher prevalence of depression and anxiety than in patients with hand eczema (32) or psoriasis (33). Furthermore, in an Indian cohort of patients with LP, Sawant et al. found that $25 \%$ were depressed. Analysing EQ-5D-3L results, the current study found that almost $60 \%$ of respondents reported depression or anxiety, and almost $70 \%$ reported pain. Considering the amount of chronic or neoplastic diseases in the current study population, these results are worrisome, since they can probably be referred to LP only and allow us to compare this disease with psoriasis and, even more generally, with other major diseases as far as impact on QoL is concerned $(34,35)$.

To our knowledge, this is the first study of this kind investigating QoL and psychopathological implications of LP, and not only its oral or erosive form, in a European population. The results show that a wider and more comprehensive approach to LP patients is needed. In addition to clinical expertise, this holistic approach should comprise psychological evaluation and support. Although cutaneous LP might heal within 1 year, most forms of this disease are chronic (1). For patients with chronic diseases, as well as for the physicians, improvement in QoL should be the main goal of treatment.

Standardized scores, such as DLQI, are needed to investigate QoL, although they might not be sufficient (36). QoL scores could help when collecting the history of the patient, guiding diagnostic and therapeutic decisions based on common treatment goals, and supporting follow-up $(37,38)$. In clinical practice, physiciandependent evaluations might vary extensively and compromise clinical efficacy. Indeed, concordance between clinician-reported measurements of disease burden and patient-related measures in previous studies appeared to be poor $(28,38)$.

However, dealing with the patients' issues holistically, as described above, is challenging given the limited time and funding for individual dermatological consultations.
Notwithstanding, QoL scores and BDI-II might speed up the collection of patient history and help to identify the most burdensome symptoms of the disease, as demonstrated for other diseases (39-41).

If an initial psychological screening indicates a need for psychological or psychiatric consultation, such a consultation should be recommended. Indeed, the need for interdisciplinary treatment is intrinsic to the polymorphic nature of LP, and the cooperation of multiple specialists as well as more thorough information about patients could enable an earlier and better prognosis.

\section{Study limitations}

A limitation of this study is the sample size of 100 patients recruited by a single institution. Nevertheless, the study may represent a more varied population, since 12 patients were not originally from Germany and our dermatology department serves different parts of Bavaria. Furthermore, scores such as EQ5D-3L and BDI-II do not address only the skin condition, but rather the general health state. However, for each patient, the DLQI was also used. Lastly, the multiple manifestations of LP were only partially differentiated in their actual impact on QoL and psychopathology.

\section{Conclusion}

This large monocentric cross-sectional survey shows a broad variability of disease-specific impact associated with LP. LP has proven to be a relevant burden to diseased patients, with significantly impaired QoL. Implementing QoL evaluations in clinical practice might prove useful and time-sparing.

Due to possible delay in the diagnostic procedures and to missing therapeutic options, LP remains a major burden for affected patients. A multimodal and interdisciplinary approach should be encouraged in order to improve diagnostics, and patients' education should be enhanced by reinforcement of support groups. Further research is needed to identify improved therapeutic strategies for LP that will have a positive effect on QoL.

\section{ACKNOWLEDGEMENT}

This study was approved by the local ethics committee (Ethics Committee University Hospital, LMU Munich, Germany, reference number 20-421)

The authors have no conflicts of interest to declare.

\section{REFERENCES}

1. Le Cleach L, Chosidow O. Clinical practice. Lichen planus. N Engl J Med 2012; 366: 723-732.

2. Browning J. Dermatology, Edited by Jean L. Bolognia Julie V. Schaffer Lorenzo Cerroni Fourth edition China: Elsevier, 2018, ISBN 978-0-7020-6275-9. Pediatric Dermatology 2018; 35: 289. 
3. González-Moles MÁ, Warnakulasuriya S, González-Ruiz I, González-Ruiz L, Ayén Á, Lenouvel D, et al. Worldwide prevalence of oral lichen planus: A systematic review and meta-analysis. Oral Dis 2021; 27: 813-828.

4. Sawant NS, Vanjari NA, Khopkar U, Adulkar S. A study of depression and quality of life in patients of lichen planus. Scientific World Journal 2015; 2015: 817481.

5. Mansur AT, Kilic Z, Atalay F. Psychological evaluation of patients with cutaneous lichen planus. Dermatol Psychosomat 2004; 5: 132-136.

6. Dalgard FJ, Gieler U, Tomas-Aragones L, Lien L, Poot F, Jemec GBE, et al. The psychological burden of skin diseases: a cross-sectional multicenter study among dermatological out-patients in 13 European countries. J Invest Dermatol 2015; 135: 984-991.

7. López-Jornet P, Camacho-Alonso F. Quality of life in patients with oral lichen planus. J Eval Clin Pract 2010; 16: 111-113.

8. Cheng H, Oakley A, Conaglen JV, Conaglen HM. Quality of life and sexual distress in women with erosive vulvovaginal lichen planus. J Low Genit Tract Dis 2017; 21: 145-149.

9. Radwan-Oczko M, Zwyrtek E, Owczarek JE, Szcześniak D. Psychopathological profile and quality of life of patients with oral lichen planus. J Appl Oral Sci 2018; 26: e20170146.

10. Rojo-Moreno J, Bagán J, Rojo-Moreno J, Donat JS, Milián MA, Jiménez Y. Psychologic factors and oral lichen planus: a psychometric evaluation of 100 cases. Oral Surg Oral Med Oral Pathol Oral Radiol Endod 1998; 86: 687-691.

11. Van Voorhees AS, Fried R. Depression and quality of life in psoriasis. Postgrad Med 2009; 121: 154-161.

12. Jafferany M, Patel A. Understanding psychocutaneous disease: psychosocial \& psychoneuroimmunologic perspectives. Int J Dermatol 2020; 59: 8-15.

13. Ghosh S, Behere RV, Sharma P, Sreejayan K. Psychiatric evaluation in dermatology: an overview. Indian J Dermatol 2013; 58: 39-43.

14. Magin PJ, Pond CD, Smith WT, Watson AB, Goode SM. A cross-sectional study of psychological morbidity in patients with acne, psoriasis and atopic dermatitis in specialist dermatology and general practices. J Eur Acad Dermatol Venereol 2008; 22: 1435-1444.

15. Finlay AY, Khan GK. Dermatology Life Quality Index (DLQI) a simple practical measure for routine clinical use. Clin Exp Dermatol 1994; 19: 210-216.

16. Group E. EQ-5D-3L. [accessed 18 April 2017] Available from: https://euroqol.org/eq-5d-instruments/eq-5d-3labout/2017.

17. Smarr KL, Keefer AL. Measures of depression and depressive symptoms: Beck Depression Inventory-II (BDI-II), Center for Epidemiologic Studies Depression Scale (CES-D), Geriatric Depression Scale (GDS), Hospital Anxiety and Depression Scale (HADS), and Patient Health Questionnaire-9 (PHQ-9). Arthritis Care Res (Hoboken) 2011; 63: S454-S566.

18. Eckstein PP. Angewandte Statistik mit SPSS: Praktische Einführung für Wirtschaftswissenschaftler. Springer Medizin Verlag, Heidelberg, 2006.

19. Field, Andy. 2013. Discovering Statistics Using IBM SPSS Statistics. 4th ed. London, England: SAGE Publications.

20. Eckey H-F, Türck M. Statistische Signifikanz (p-Wert). WiStWirtschaftswissenschaftliches Studium 2006; 35: 415-418.

21. Lehmann EL. Consistency and unbiasedness of certain nonparametric tests. Ann Math Statist 1951; 22: 165-179.

22. Hedderich J, Sachs L. Angewandte Statistik. Springer-Verlag
Berlin, Heidelberg, 2016.

23. Fahrmeir L, Heumann C, Künstler R, Pigeot I, Tutz G. Statistik: Der weg zur datenanalyse. Springer-Verlag Berlin, Heidelberg, 2016.

24. Bortz J, Lienert GA. Kurzgefasste Statistik für die klinische Forschung: Leitfaden für die verteilungsfreie Analyse kleiner Stichproben. Springer Medizin Verlag, Heidelberg, 2008.

25. Bender R, Lange $\mathrm{S}$. Was ist der $\mathrm{p}$-Wert? Deutsche Medizinische Wochenschrift 2001; 126: T39-T40.

26. Bland JM, Bland D. Statistics notes: one and two sided tests of significance. BMJ 1994; 309: 248.

27. Manolache L, Seceleanu-Petrescu D, Benea V. Lichen planus patients and stressful events. J Eur Acad Dermatol Venereol 2008; 22: 437-441.

28. Picardi A, Amerio P, Baliva G, Barbieri C, Teofoli P, Bolli S, et al. Recognition of depressive and anxiety disorders in dermatological outpatients. Acta Derm Venereol 2004; 84: 213-217.

29. Picardi A, Abeni D. Stressful life events and skin diseases: disentangling evidence from myth. Psychother Psychosom 2001; 70: 118-136.

30. Allen CM, Beck FM, Rossie KM, Kaul TJ. Relation of stress and anxiety to oral lichen planus. Oral Surg Oral Med Oral Pathol 1986; 61: 44-46.

31. Hong J, Koo B, Koo J. The psychosocial and occupational impact of chronic skin disease. Dermatol Ther 2008; 21: 54-59.

32. Boehm D, Schmid-Ott G, Finkeldey F, John SM, Dwinger C, Werfel $T$, et al. Anxiety, depression and impaired healthrelated quality of life in patients with occupational hand eczema. Contact Dermatitis 2012; 67: 184-192.

33. Dowlatshahi EA, Wakkee M, Arends LR, Nijsten T. The prevalence and odds of depressive symptoms and clinical depression in psoriasis patients: a systematic review and meta-analysis. J Invest Dermatol 2014; 134: 1542-1551.

34. Rapp SR, Feldman SR, Exum ML, Fleischer AB, Jr, Reboussin DM. Psoriasis causes as much disability as other major medical diseases. J Am Acad Dermatol 1999; 41: 401-407.

35. Feldman SR. Psoriasis causes as much disability as other major medical diseases. J Am Acad Dermatol 2020; 82: 256-257.

36. Connor $\mathrm{CJ}$. Management of the psychological comorbidities of dermatological conditions: practitioners' guidelines. Clin Cosmet Investig Dermatol 2017; 10: 117-132.

37. Finlay $A Y$, Salek MS, Abeni $D$, Tomás-Aragonés $L$, van Cranenburgh OD, Evers AW, et al. Why quality of life measurement is important in dermatology clinical practice: an expert-based opinion statement by the EADV Task Force on Quality of Life. J Eur Acad Dermatol Venereol 2017; 31: 424-431.

38. Richards HL, Fortune DG, Weidmann A, Sweeney SKT, Griffiths CEM. Detection of psychological distress in patients with psoriasis: low consensus between dermatologist and patient. $\mathrm{Br}$ J Dermatol 2004; 151: 1227-1233.

39. Donnarumma M, Fattore D, Greco V, Ferrillo M, Vastarella M, Chiodini $\mathrm{P}$, et al. How to increase adherence and compliance in acne treatment? A combined strategy of SMS and visual instruction leaflet. Dermatology 2019; 235: 463-470.

40. Marasca C, Napolitano M, Monfrecola G, Masarà A, Annunziata MC, Donnarumma M, et al. Quality of life in people living with patients suffering from hidradenitis suppurativa. J Eur Acad Dermatol Venereol 2020; 34: e342-34e3.

41. Osman OT, Mufaddel A, Almugaddam F, Augusterfer EF. The psychiatric aspects of skin disorders. Exp Rev Dermatol 2011; 6: 195-209. 